\title{
A Case Report of Laryngo Tracheal Trauma with a Communicated Thyroid Cartilage Fracture
}

\author{
Saif Ullah Mir ${ }^{1 *}$, Atif Hafeez Siddique ${ }^{2}$, Saad shakeel ${ }^{3}$, Mubashir Razzaq ${ }^{4}$ and Kiran Shafique ${ }^{5}$ \\ ${ }^{1}$ Dow University Of Health Sciences Karachi Pakistan \\ ${ }^{2}$ Dow University Of Health Sciences Karachi Pakistan
}

${ }^{3}$ Dow University Of Health Sciences Karachi Pakistan

${ }^{4}$ Dow University Of Health Sciences Karachi Pakistan

${ }^{5}$ Dow University Of Health Sciences Karachi Pakistan

*Corresponding author: Saifullah Mirm, Dow University Of Health Sciences Karachi Pakistan

\begin{tabular}{|c|c|}
\hline ARTICLE INFO & ABSTRACT \\
\hline Received: 幽 August 15, 2019 & Citation: Saif Ullah Mir, Atif Hafeez Siddique, Saad shakeel, Mubashir Razzaq, Kiran S. \\
\hline Published: 豐 August 26, 2019 & $\begin{array}{l}\text { A Case Report of Laryngo Tracheal Trauma with a Communicated Thyroid Cartilage } \\
\text { Fracture. Cuba, 1987-2018. Biomed I Sci \& Tech Res 20(5)-2019. BISTR. MS.ID.003518. }\end{array}$ \\
\hline
\end{tabular}

\section{Introduction}

Laryngeal trauma is a life threating entity and if not treated properly can result in serious morbidity due to sub glottic stenosis leaving the patient dependent on a tracheostomy [1]. The incidence of laryngeal trauma is 1 in 30000 admission to the emergency department. Laryngeal trauma may affect children and much less than adults [2]. Here we present a further case of laryngeal trauma which was successful managed. We emphasize the importance of a structured management plan for laryngeal tracheal trauma. Such measure has been shown to increase patient survival and improve long term functional outcome to breathing, speech and swallowing [3].

Laryngeal tracheal trauma is seen plentiful in trauma patients and can go unrecognized and under treated due to severity. Endo laryngeal stent are reserved for the use in severe laryngeal trauma cases or injury that disturb the anterior commissure of the vocal fold [2]. The transitory role in management of laryngeal tracheal trauma is to first protect and second reconstruct the airway. Definitive management encompass in staging of the disorder (in this situation by way of Scheffer classification) accompanied by means of meticulous anatomical reconstruction at the side of stenting of the airway to avert sub glottis and tracheal stenosis are important in its treatment. It may be due to non-penetrating or penetrating mechanism [2]. It may be associated with damage to the laryngeal framework, damage to laryngeal nerve, great vessel injury [3].

\section{Case}

A 40 years old male, known case of hypertension for four years presented to the emergency department of Dr. Ruth KM Pfau Civil
Hospital Karachi in 2019 with the history of cutthroat via flour mill machine. In keeping with the patient, he was in his usual state of health 2 days before this incident when his shirt got stuck in flour mill machine while working. He informed that a part of gadget struck his neck lacerating it shown in Figure 1. They took him to the closest hospital in Larkana $500 \mathrm{kms}$ from Karachi. Due to lack of facilities there they only stitched his wound and referred him to Civil Hospital Karachi. Here, he was presented after one day of injury. Patient was little drowsy at the time of examination. On clinical examination major laceration was found from right sternocleidomastoid muscle to left sternocleidomastoid muscle in anterior triangle of neck $6 \mathrm{~cm}$ above the sternal notch $5 \times 10 \mathrm{~cm}$ with exposed cartilage and free communication with larynx. There was a defect in midline of thyroid cartilage resulting in its shattering, vocal cords were not exposed. He had 3 episodes of vomiting after injury.

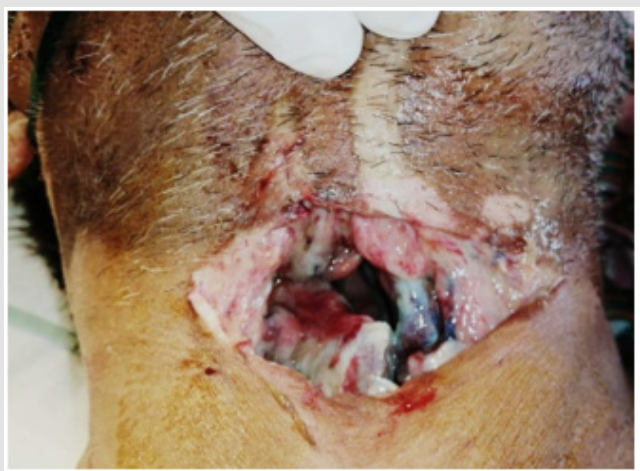

Figure 1: Showing 2-day old neck injury by mechanical belt. 
He was hemo-dynamically stable. Pre and post-operative neck CT sagittal and axial view was done shown in Figures 2 \& 3. Ct scan shows communicated fracture of thyroid cartilage with posterior displacement widening of the glottis showing in Figure 4 without any evidence of great vessel injury. He was shifted immediately to the operation room where intubation and thyroid repair was done under local anesthesia shown in Figure 5 and airway was secured by doing tracheostomy. Major vessels of neck found to be intact, no swelling noted in the neck. Primary repair of thyroid cartilage is done using 5-0 proline plus double closure was done for the pharyngeocutanneous junction shown in Figure 6. Wound was closed in layers. Skin closure was done using 3-0 ethanol. An endotracheal tube stent was fashioned due to the non- availability of a Montgomery tube. The distal end was anchored to the anterior neck skin . Patient was put on ventilator for 48 hours.

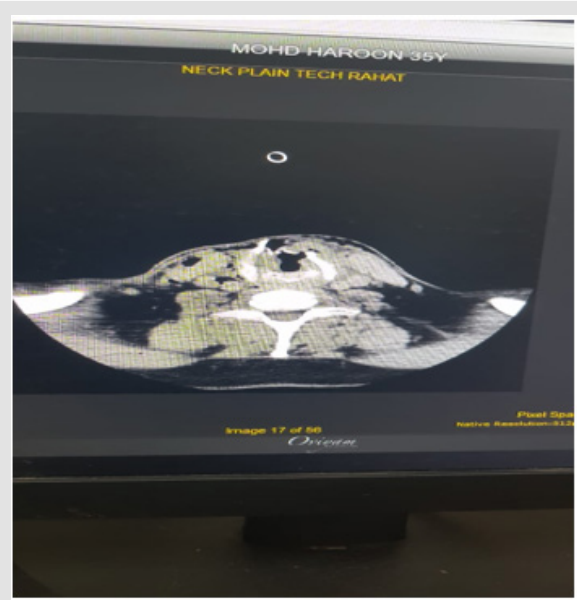

Figure 2: Pre-operative CT (axial cuts) showing communicated fracture of thyroid cartilage.

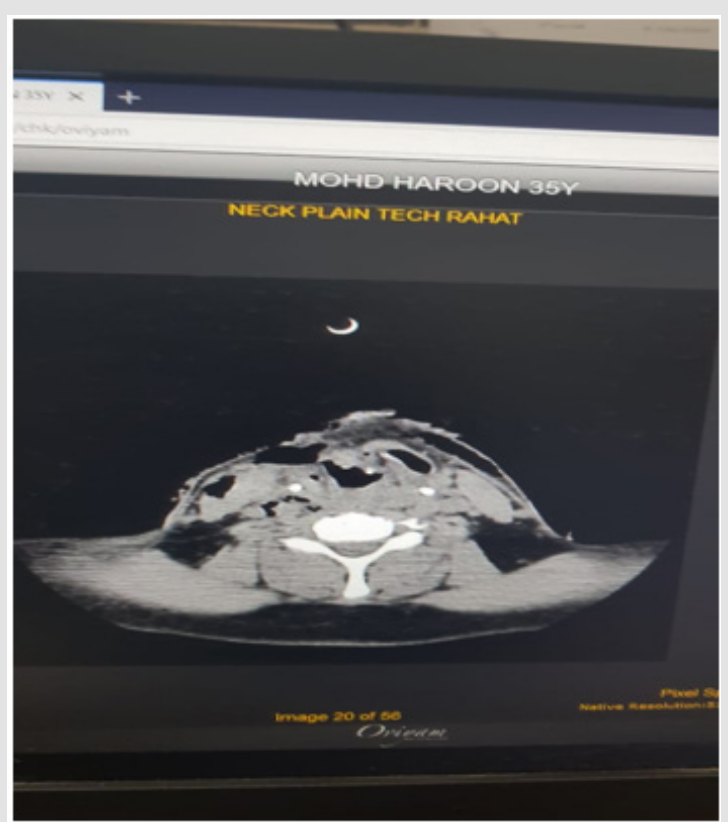

Figure 3: Pre-operative axial view demonstrates right side pharyngo-cutaneous fistula.

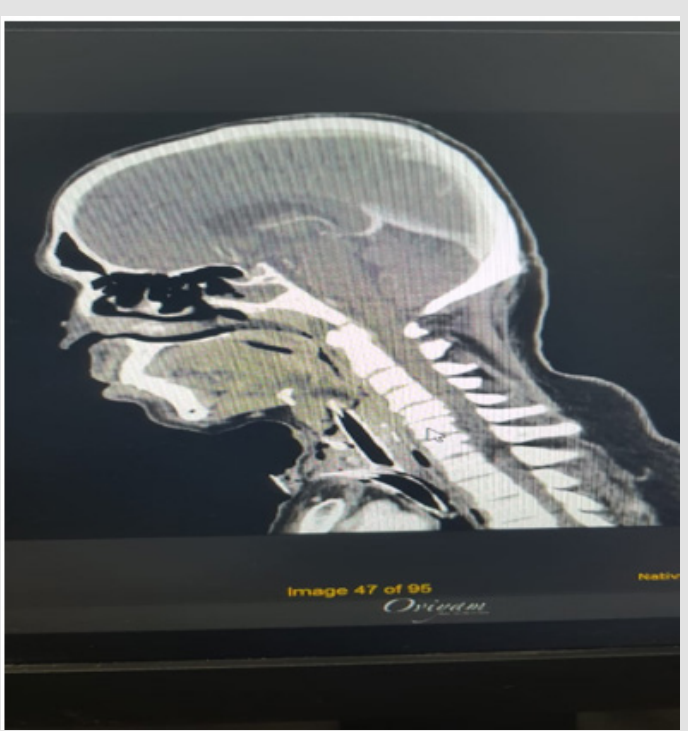

Figure 4: Post-operative CT sagittal view showing tracheal tube in situ in pace along with pharyngeal stent.

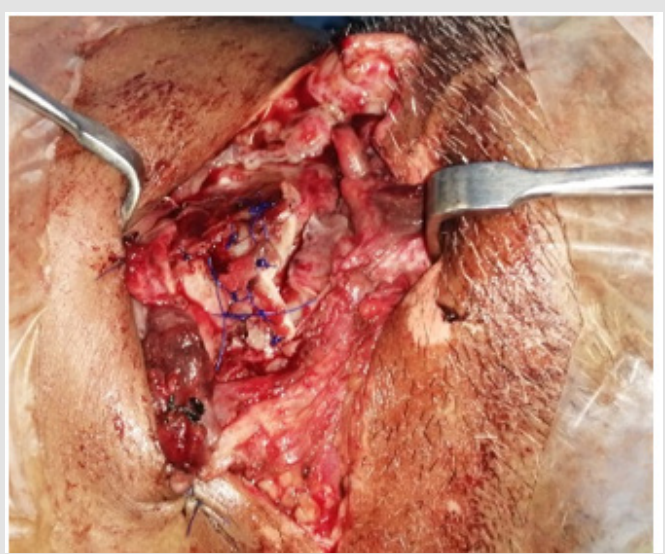

Figure 5: Shows thyroid cartilage repair with 5-0 proline with special attention to repair of the anterior commissure and glottis.

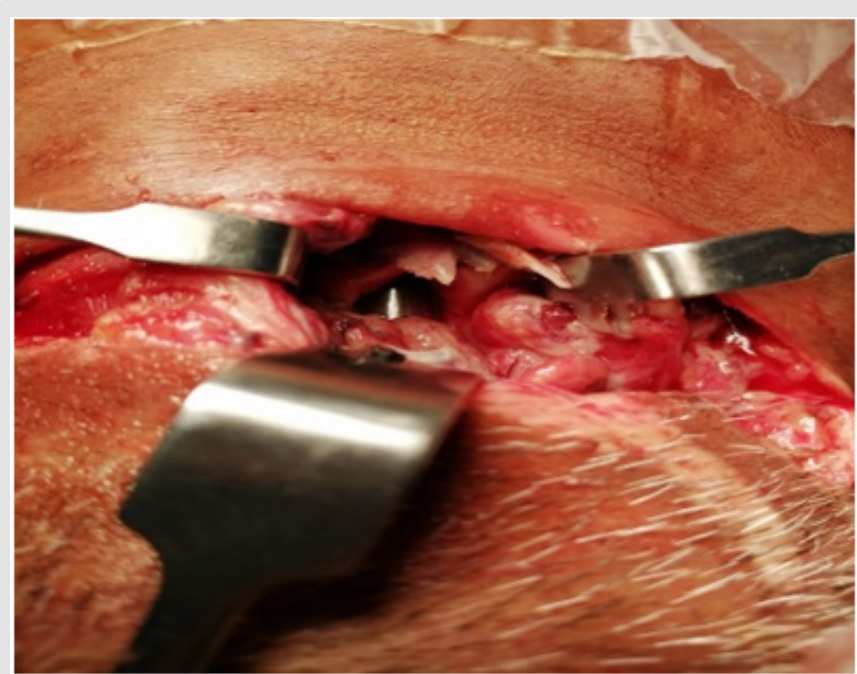

Figure 6: Showing phayngotracheal stent in place before commencement of formal repair. 


\section{Discussion}

Injuries of larynx and trachea can be grouped into blunt and penetrating. Blunt trauma to the neck requires a systemic evaluation of laryngeotracheal, the esophagus and cervical spine [4]. Penetrating laryngotracheal trauma are unusual. However, these kinds of injuries are related with significant morbidity and mortality it establishes $5-10 \%$ of all cases grasped in emergency room. Neck wounds extend below the platysma are classified as penetrating injury [5]. Laryngeal tracheal injury can categorize by position (supra glottis, Trans glottis, cricoid, or tracheal) type (hematoma, mucosal tear, laceration cartilage fracture, or laryngeal tracheal disruption) and degree of severity. Evaluating the patient along these facets is the foremost part of the investigation with laryngeal tracheal trauma [6]. This can be a challenge, since relatively minimal sign and symptoms may conceal severe injury.

A secondary survey should be completed to investigate for symptoms and sign of subcutaneous emphysema, hoarseness, stridor, damage of normal thyroid prominence, hemoptysis, deviance of larynx, loss of crepitus and respiratory distress [6]. If sign of respirational distress like dyspnea and stridor are progressive it calls for instant assessment, a tracheostomy ought to be executed. Vocal cords should be examined, and inquiry should be done for voice transformation. Whatever time laryngeal tracheal injury is alleged intubation should be reinforcing with prodigious precaution Control tracheostomy under local anesthesia is always ideal Enactment of tracheostomy can be tremendously problematic with altered anatomy and utmost of such patient also have bilateral vocal cord paralysis due to sprawl or tearing of recurrent laryngeal nerve [7].

In current case, laceration was almost extending from right sternocleidomastoid to left sternocleidomastoid. In our case the cartilage was wide-open. Damage to trachea was present, no mutilation of vocal cord, no injury to major vessel of neck was noted and tracheostomy was done to protect the airway. Crucial closure of the cartilage defect was complete using 5-0 prolene and two layered closure was done for pharyngo-cutaneous junction. Following this a formal tracheostomy was done. The patient was placed on a ventilator for $48 \mathrm{hr}$ and antibiotic treatment. Konobu
T el al. [8] reported 4 cases with laryngotracheal injury owing to neck trauma. They execute laryngotracheoplasty by absorbable material within eight hours after trauma. Two patients go through tracheostomy at the lower level of laryngotracheal injury. Three cases were cured successfully without chief airway delinquent. One expired due to hemorrhagic shock. The key point is that penetrating laryngotracheal trauma should be measured as a solemn airway injury which may be hidden under superficial small wound.

\section{Conclusion}

Laryngotracheal injury is infrequent and life-threatening complaint with long term management challenge. As per our study we acclaim primary closure if the precise nature of injury is known as the consequence is satisfactory. Mortality and morbidity can be significantly reduced by appropriate airway control. Endotracheal intubation maybe challenging in patient with penetrating injury. Repair can be performed with good end result. In patient with slight injury tracheostomy doesn't seem to be necessary. Though, further studies are required with increased sample size are required.

\section{References}

1. Sofferman RA (1981) Management of laryngotracheal trauma. The American Journal of Surgery 141(4): 412-417.

2. Parida PK, Kalaiarasi R, Alexander A (2018) Management of Laryngotracheal Trauma: A Five-Year Single Institution Experience. Iranian journal of otorhinolaryngology 30(100): 283-290.

3. Thevasagayam MS, Pracy P (2005) Laryngeal trauma: a systematic approach to management. Trauma 7(2): 87-94.

4. Omakobia E, Micallef A (2016) Approach to the patient with external laryngeal trauma: the Schaefer classification. Otolaryngol (Sunnyvale) 6(2): 230 .

5. Varghese A (2013) Penetrating neck injury: a case report and review of management. Indian Journal of Surgery 75(1): 43-46.

6. Lee WT, Eliashar R, Eliachar I (2006) Acute external laryngotracheal trauma: diagnosis and management. ENT Ear Nose Throat J 85(3): 179184.

7. Sethi RK, Khatib D, Kligerman M, Kozin ED, Gray ST, et al. (2019) Laryngeal fracture presentation and management in United States emergency rooms. The Laryngoscope.

8. Konobu T, Nakamura T, Hata M, Ueyama T, Norimoto K, et al. (2005) Acute penetrating neck trauma presenting with laryngotracheal injury. Kyobu geka. The Japanese journal of thoracic surgery 58(6): 475-480.

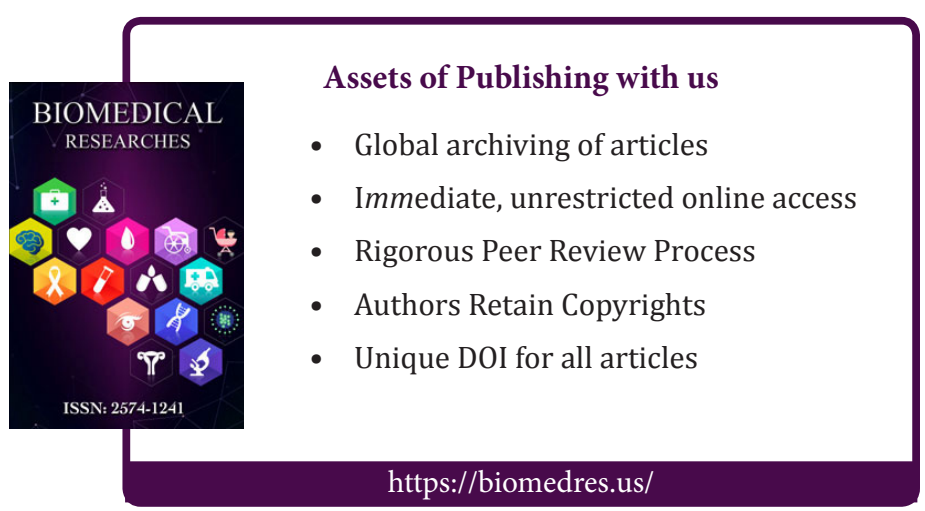

\section{ISSN: 2574-1241}

DOI: 10.26717/BJSTR.2019.20.003518

Saifullah Mir. Biomed J Sci \& Tech Res

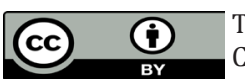

This work is licensed under Creative Commons Attribution 4.0 License

Submission Link: https://biomedres.us/submit-manuscript.php 